\title{
Effects of Radiation on MEMS
}

\author{
Herbert R. Shea* \\ Microsystems for Space Technologies Laboratory, EPFL, Neuchâtel, Switzerland
}

\begin{abstract}
The sensitivity of MEMS devices to radiation is reviewed, with an emphasis on radiation levels representative of space missions. While silicon and metals generally do not show mechanical degradation at the radiation levels encountered in most missions, MEMS devices have been reported to fail at doses of as few krad, corresponding to less than one year in most orbits. Radiation sensitivity is linked primarily to the impact on device operation of radiation-induced trapped charge in dielectrics, and thus affects most strongly MEMS devices operating on electrostatic principles. A survey of all published reports of radiation effects on MEMS is presented. The different sensing and actuation physical principles and materials used in MEMS are compared, leading to suggested was to increase radiation tolerance by design, for instance by choice of actuation principle or by electrical shielding of dielectrics.
\end{abstract}

Keywords: MEMS, radiation damage, space, dielectric charging

\section{INTRODUCTION}

The reliability of MEMS has increased rapidly in the past 10 years, with highly reliable micromachined devices being used by the dozens in modern automobiles, and with MEMS accelerometers and gyroscopes becoming commonplace in many consumer handheld devices. MEMS devices are sold by the hundreds of millions per year [1], with failure rates below ppm. How to determine the failure modes of MEMS, perform accelerated testing, and improve reliability is an active field, with recent progress summarized for instance in [4].

Most studies of MEMS reliability do not focus on radiation, as this is a concern principally for devices used in spacecraft or near nuclear reactors. We will in this paper focus on radiation effects representative of the range encountered in most space missions, and not of those encountered in reactor cores.

MEMS devices for use in space [2][7][17] cover the same wide range of applications areas as MEMS on Earth, but have different environmental operating requirements, in particular in regards to radiation, thermal cycling, vacuum, and shock and vibration. The interest in MEMS for space comes from two main drivers: 1) some missions require MEMS, such as the AFM on the successful Phoenix Mars mission [3], and 2) reducing spacecraft mass and cost by a high level of miniaturization, for which MEMS are an essential enabling technology. For instance optical MEMS are key for spacebased telescopes, such as the multi-slit mask (Near Infrared Multi-Object Spectrograph (NIRSpec) for the for James Webb Space Telescope (JWST) under development at NASA's Goddard Space Flight Center.

Increasing the radiation hardness of integrated circuits is a field in which key parameters are understood [5], though there is still rapid progress in view of the ever-decreasing critical dimensions of CMOS transistors. This maturity is in part possible because all ICs are based on semiconductors, principally silicon, and have the transistor as central elements.

In contrast, MEMS can be fabricated from a wide range of materials ( $\mathrm{Si}$, polymer, metals, ceramics) and rely on many different physical principles (piezo, electrostatic, thermal, electromagnetic) for sensing and actuation, with a broad spectrum of applications (microfluidics, displays, inertial navigation, RF and optical switching) Therein lies one major challenge in predicting and improving reliability of MEMS, and radiation testing is no exception, to which the many different types of radiation must be added (photons, protons, electrons, heavy ions, all of which can have energies from $\mathrm{keV}$ to $\mathrm{GeV}$...). Another complexity one must address for MEMS under radiation is the interplay between the MEMS sensor or actuator and the associated control electronics, in particular when the latter are monolithically integrated with the former, as is the case for the ADXL series accelerometers from Analog Devices and the DMD devices from Texas Instruments.

*herbert.shea@epfl.ch; http://lmts.epfl.ch

Reliability, Packaging, Testing, and Characterization of MEMS/MOEMS and Nanodevices X,

edited by Sonia Garcia-Blanco, Rajeshuni Ramesham, Proc. of SPIE Vol. 7928, 79280E

(C) 2011 SPIE - CCC code: 0277-786X/11/\$18 - doi: 10.1117/12.876968

Proc. of SPIE Vol. 7928 79280E-1 
This paper starts in section 2 with a classification of MEMS devices in the context of radiation susceptibility. The paper then follows the structure and summarizes the review data presented in ref [6]: overview of effect of radiation on materials (section 3), space radiation environment (section 4), review of published data on radiation testing of MEMS (section 5) and mitigation strategies (section 6).

\section{MEMS CLASSIFICATION FOR RADIATION EFFECTS}

We attempt here to make a classification of MEMS with regards to radiation effects. Earlier attempts at classifying the reliability of MEMS have focused on contacting parts, since stiction and surface effects are indeed major MEMS failure modes, but this ins not the main concern for radiation damage in MEMS.

The degradation of MEMS devices due to radiation is a complex interplay of changes to the materials and the sensing and actuation physical principle. For instance, there is nearly no change in the Young's modulus of silicon following Gamma irradiation. Therefore the resonant frequency of a silicon cantilever or proof mass is not expected to permanently change following such irradiation. However gamma irradiation can lead to large amounts of trapped charge in dielectrics. Therefore if a capacitive readout is used to sense resonance frequency, a large change in device parameters may be experienced. If an optical technique (such as laser Doppler vibrometry) is used to measure device frequency, no change will be observed.

Table 1 gives a preview of the detailed survey in section (see Table 4 in section 5). When determining a test and qualification methodology for MEMS, we suggest limiting the scope to one box of table 1 so as to keep the physics of failure in a well-defined region of the very large parameter space. Packaging always plays a large role in the reliability of a MEMS device, and this is naturally also the case for radiation studies, where the package can act as an effective shield.

Table 1. Simplified classification of MEMS. Susceptibility to radiation-induced failures labeled from "“- -" very susceptible to “-_, to "+" to "++" highly resistant. This a general view, ignoring any specific design adaptations that may have been made to improve radiation hardness.

\begin{tabular}{|c|c|c|c|c|c|}
\hline $\begin{array}{r}\text { Physical } \\
\text { Rinciple } \\
\text { Material }\end{array}$ & $\begin{array}{c}\text { Capacitive } \\
\text { (electrostatic) }\end{array}$ & Electromagnetic & $\begin{array}{l}\text { Piezoresistive or } \\
\text { piezoelectric }\end{array}$ & Electrothermal & Optical sensing \\
\hline Silicon & $\begin{array}{l}\text { NIEL: ++ } \\
\text { Ionizing: -- }\end{array}$ & $\begin{array}{l}\text { NIEL: ++ } \\
\text { Ionizing: }++\end{array}$ & $\begin{array}{l}\text { NIEL: + } \\
\text { Ionizing: - }\end{array}$ & $\begin{array}{l}\text { NIEL: ++ } \\
\text { Ionizing: ++ }\end{array}$ & $\begin{array}{l}\text { NIEL: ++ } \\
\text { Ionizing: }++\end{array}$ \\
\hline Glass / ceramics & $\begin{array}{l}\text { NIEL: ++ } \\
\text { Ionizing: -- }\end{array}$ & $\begin{array}{l}\text { NIEL: ++ } \\
\text { Ionizing: ++ }\end{array}$ & $\begin{array}{l}\text { NIEL: + } \\
\text { Ionizing: - }\end{array}$ & $\begin{array}{l}\text { NIEL: ++ } \\
\text { Ionizing: ++ }\end{array}$ & $\begin{array}{l}\text { NIEL: + } \\
\text { Ionizing: ++ }\end{array}$ \\
\hline Metals & $\begin{array}{l}\text { NIEL: ++ } \\
\text { Ionizing: -- }\end{array}$ & $\begin{array}{l}\text { NIEL: ++ } \\
\text { Ionizing: }++\end{array}$ & $\begin{array}{l}\text { NIEL: + } \\
\text { Ionizing: - }\end{array}$ & $\begin{array}{l}\text { NIEL: ++ } \\
\text { Ionizing: }++\end{array}$ & $\begin{array}{l}\text { NIEL: ++ } \\
\text { Ionizing: ++ }\end{array}$ \\
\hline SU-8 & $\begin{array}{l}\text { NIEL: + } \\
\text { Ionizing: -- }\end{array}$ & $\begin{array}{l}\text { NIEL: }+ \\
\text { Ionizing: ++ }\end{array}$ & $\begin{array}{l}\text { NIEL: + } \\
\text { Ionizing: - }\end{array}$ & $\begin{array}{l}\text { NIEL: + } \\
\text { Ionizing: ++ }\end{array}$ & $\begin{array}{l}\text { NIEL: + } \\
\text { Ionizing: ++ }\end{array}$ \\
\hline PDMS & $\begin{array}{l}\text { NIEL: - } \\
\text { Ionizing: -- }\end{array}$ & $\begin{array}{l}\text { NIEL: - } \\
\text { Ionizing: + }\end{array}$ & $\begin{array}{l}\text { NIEL: - } \\
\text { Ionizing: - }\end{array}$ & $\begin{array}{l}\text { NIEL: - } \\
\text { Ionizing: + }\end{array}$ & $\begin{array}{l}\text { NIEL: - } \\
\text { Ionizing: + }\end{array}$ \\
\hline
\end{tabular}

\section{SUMMARY OF RADIATION DAMAGE ON MATERIALS}

The effect of radiation on materials is well described in several books such as [13]. We briefly summarize in this section the main degradation processes and effects as required background information for the MEMS-centric discussion in section 5 . 


\subsection{Degradation Processes}

Energetic particles and photons cause damage by transferring energy to the materials they penetrate. The energy loss mechanisms are complex, but the type of damage can be classified in two consequences: a) atomic displacement (i.e. moving atoms due to the collisions) and b) ionization (i.e. creating electron-hole pairs). Figure 1 provides an overview of the effects that radiation can have on devices. Note that most particles will lead to both types of damage. A highenergy particle will lead to a string of collisions as it loses energy, with interaction cross-section increasing with decreasing energy, leading to a cluster of damage at the end of its trajectory.

The global effect of the many different types of radiation on components can be summarized by the quantity of energy deposited by the radiation. The SI unit is the Gray $(1 \mathrm{~J} / \mathrm{kg})$, but the unit $\mathrm{rad}\left(1 \mathrm{rad}=10^{-2} \mathrm{Gray}\right)$ is still in common use.

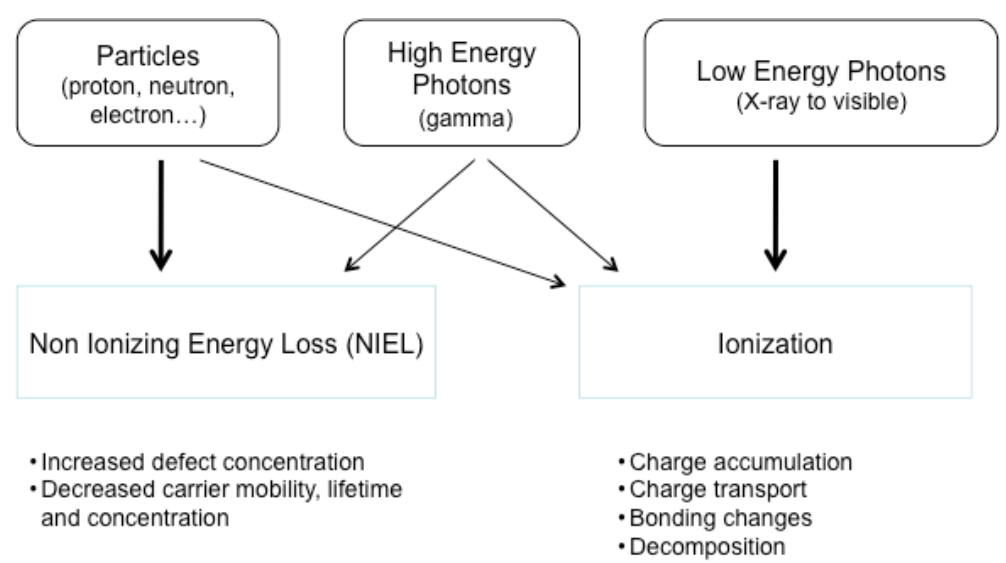

Figure 1: Summary of radiation induced degradation effects, ignoring transient effects, adapted from table 5.1 of [21]

\subsubsection{Non-ionizing radiation loss (NIEL)}

A fraction of the energy transferred to the target from energetic particles or even from photons results in the transfer of momentum to atomic nuclei, which can result in atoms being moved from their rest position in the lattice, leaving vacancies or defects behind. The process of atomic displacement is referred to as "bulk damage" [13]. Even photons of sufficient energy can give rise to this non-ionizing radiation loss (NIEL), or displacement damage, component of radiation.

Displacement damage has a number of consequences. The most relevant for electronic devices is the reduction in minority carrier lifetime, the reduction of carrier mobility, and the removal of carriers (by interaction with defects). The damage caused by most particles is of the same general type. For silicon, equivalence has been shown between a fluence of $1 \mathrm{MeV}$ electrons and different fluences of other particles.

\subsubsection{Ionization}

Most of the energy lost from radiation interacting with an absorber is ultimately converted to electron-hole pairs (the energy required is only $18 \mathrm{eV}$ for $\mathrm{SiO}_{2}$ ). Electrons and holes have very different mobilities. The electrons and holes increase the conductivity of the sample (even of insulators), and the holes can become trapped in insulators $\left(\mathrm{SiO}_{\mathrm{x}}, \mathrm{SiN}_{\mathrm{x}}\right)$, leading to serious degradation of MOS and MEMS devices. This Total Ionizing radiation Dose (TID) leads to an accumulation of electrically active defects. The biasing of a sample is important because the electric field from the bias will drive the electrons and holes, and thus change the effect on the device of ionizing radiation.

In polymers the ionization can break bonds and even create new ones. The mechanical properties of polymers can be strongly modified for ionizing and non-ionizing radiation. 


\subsection{Degradation Consequences}

The consequences of damage depend on whether the damage is due to atomic displacement or to ionization, whether the effects are transient or long-lived, and what type of material absorbed the radiation (we will distinguish between metal, semiconductor, and insulator). Additionally, one can also distinguish between changes in the mechanical vs. electrical properties of the materials.

\subsubsection{Metals}

There are no reports of important metal degradation by radiation in space [21]. In nuclear reactor cores the neutron fluxes are high enough to significantly reduce the mechanical strength of metals, or render them brittle. For space missions, metals are deemed to be radiation tolerant.

\subsubsection{Semiconductors}

Displacement damage leads to electrical and mechanical changes. The electrical changes are due to the change in minority carrier lifetime and concentration, which can have an important effect on p-n junctions (rectifiers and bipolar transistors, as well as solar cells). FET and MOS devices are much less sensitive to this effect.

For mechanical changes, even at the high end of typical doses for space (Mrad), the amount of damage to silicon is rather small and the Young's modulus is not markedly changed. For electronics and packaging the effect can be ignored. For MEMS devices such as resonators, which are sensitive to ppm change in Young's modulus, further investigation is required, see references [52] and [11].

\subsubsection{Insulators}

In optical materials displacement damage lead to color centers. For electronic or structural materials, displacement damage leads only to very small effects (compared to semiconductors) because dielectrics are typically glassy (amorphous), and there is thus no ordered lattice to disrupt. The dielectric retains its insulating properties even when a few atoms are displaced. Also, doping levels are not important, unlike for semiconductors.

Ionization of insulators has a major impact on microelectronic devices, in particular for LSI and VLSI MOS ICs. The harmful effects of ionization in dielectrics are diverse, but are related either to a dramatic decrease in resistance of the dielectric, or to accumulation of trapped charge. For electrostatically actuated MEMS devices, trapped charge can cause device failure.

\section{SPACE RADIATION ENVIRONMENT}

The radiation environment in space is complex, and is concisely described in references [7], [21] and [22]. The radiation environment depends not only on the orbit but also on the 11-year solar cycle. Software packages (e.g., SPENVIS [12]) exist that combine these different models allowing rapid determination of the dose and type of radiation exposure for Earth orbits.

We present here the radiation on the outside of the spacecraft. The energy and dose reaching the devices inside the spacecraft depend on the details of the spacecraft geometry and its expected orientation. For large (multi-ton) satellites, the electronics inside the spacecraft may be very well shielded simply by the structure and surrounding components.

The main types of radiation encountered near Earth consist of:

- Trapped radiation: energetic electrons and protons magnetically trapped around the earth (the Van Allen belts). They consist of electrons of energy up to a few $\mathrm{MeV}$, and protons of up to several hundred $\mathrm{MeV}$.

- Solar Energetic particles: mostly highly energetic protons, up to $300 \mathrm{MeV}$. The intensity varies greatly in time, especially the 11 year solar cycle, since the proton flux is associated with solar flares. UV and X-ray burst are also produced, as well as solar cosmic rays.

- Galactic cosmic-rays: continuous low flux of highly energetic (1 MeV to $1 \mathrm{GeV})$ particles, mostly protons, alpha particles, but also include heavy ions. 
- Secondary radiation: radiation generated when the above radiation interacts with materials in the spacecraft, notably with shielding. Includes primarily electron-induced bremsstrahlung, but also secondary electrons, and other particles such as secondary neutrons.

Table gives approximate values of energy deposited in a component for a low Earth orbit (LEO) and for a geostationary orbit (GEO), without shielding and with shielding equivalent to $4 \mathrm{~mm}$ thickness of aluminum.

Table 2: representative annual radiation doses for LEO and GEO orbits

\begin{tabular}{|l|l|l|}
\hline \multicolumn{1}{|c|}{ Trajectory, shielding } & \multicolumn{1}{|c|}{ Predominant particles } & Dose deposited per year \\
\hline LEO, outside S/C & Trapped electrons & $>100 \mathrm{krad}$ \\
\hline LEO, $4 \mathrm{~mm} \mathrm{Al} \mathrm{equivalent}$ & Trapped protons & $1 \mathrm{krad}$ \\
\hline GEO, outside S/C & Trapped electrons & $>10$ '000 krad \\
\hline GEO, $4 \mathrm{~mm} \mathrm{Al} \mathrm{equivalent}$ & Bremsstrahlung + solar protons & $10 \mathrm{krad}$ \\
\hline
\end{tabular}

Space missions typically last several years, and operate in a radiation environment with dose rates of order $1 \mathrm{rad} / \mathrm{hour}$. Testing however must be done in hours or days (dose rates from $36 \mathrm{rad} / \mathrm{hour}$ to $36 \mathrm{krad} /$ hour are commonly used for ${ }^{60} \mathrm{Co}$ irradiation). Despite the complexity of the actual space radiation environment, accelerated radiation testing methods have been developed using mono-energetic particles for microelectronic devices. There is however no standard testing procedures established for MEMS, though studies are ongoing, such as MEMSRAD [10]. A major challenge for MEMS is the vast diversity of materials and sensing schemes, see Table 1.

For MEMS devices, we must ask how deep the particles will penetrate in the package and in the device. Fig. 2 is a plot of stopping range of protons and electrons. Since the interaction cross-section increase as ion energy decreases, more damage is created at the end of the particle's trajectory, see Fig 3.

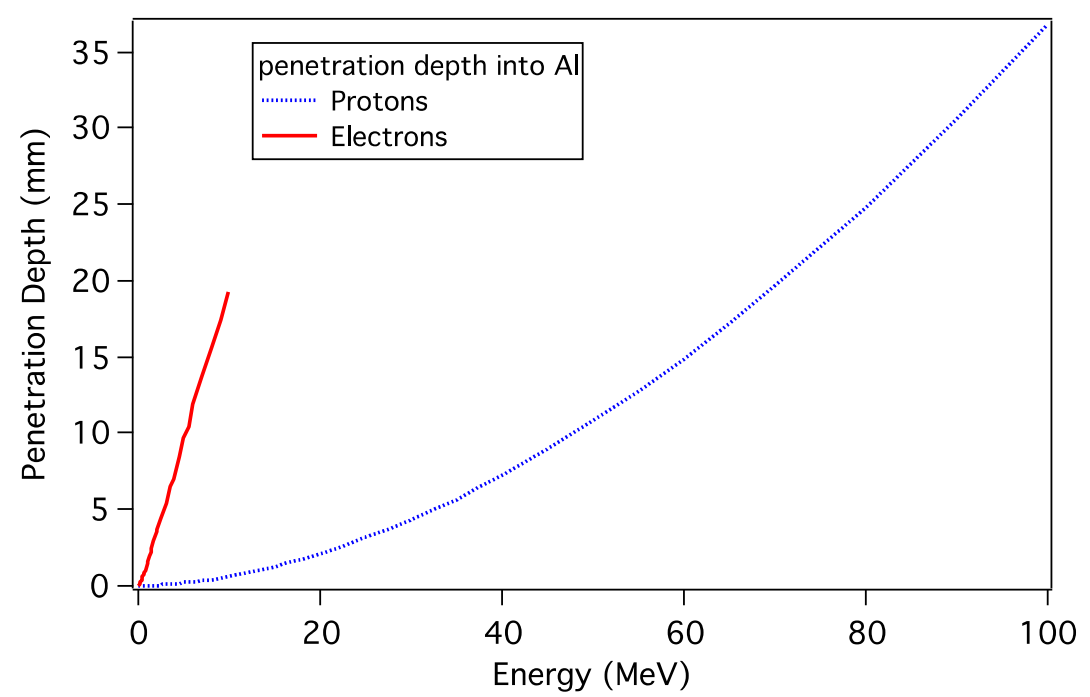

Figure 2. Penetration depth vs. energy for protons and electros in Aluminum. $4 \mathrm{~mm}$ of Al shielding is often considered as a standard value for spacecraft to estimate radiation levels. Electron data from [21] and Proton data computed with SRIM [9]. 


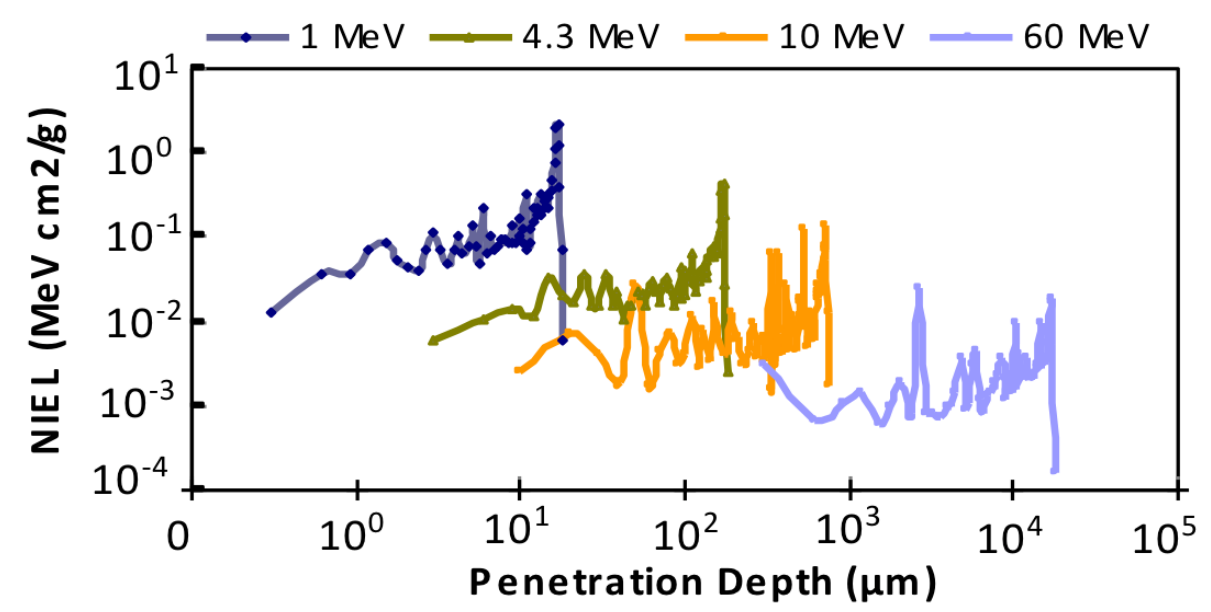

Figure 3. NIEL as a function of penetration depth for protons in silicon computed using SRIM [9], from J. Gomes and H. Shea [11].

\section{REVIEW OF PUBLISHED DATA ON RADIATION TESTING OF MEMS}

Few radiation tests have been performed on MEMS devices (less than thirty published papers). As mentioned in the introduction, it can be challenging to distinguish degradation of the MEMS sensor or actuator from damage to the control electronics. While this may seem like a meaningless distinction from a qualification perspective, this is an important point to resolve in order to gain an understanding of the failure mode, a necessary step to increasing the device's radiation tolerance.

On the low-tolerance end, one finds that most electrostatically operated MEMS devices degrade between 10 and 100 $\mathrm{krad}$, unless special steps are taken to render the device insensitive to charge build-up in dielectric layers. Tests on accelerometers and RF switches showed a marked change in calibration at doses above 30 krad [25],[26],[27]. Those failures were attributed to trapped charge in dielectric films. These doses are for unpackaged devices so that the sensor element is directly irradiated. Similar doses on packaged devices would lead to significantly less damage.

On the other extreme, micro-engines from Sandia National Labs in Albuquerque, NM, USA were reported to only change their behavior at doses of order $10 \mathrm{Mrad}$, in some cases over $1 \mathrm{Grad}$ [28]. Those devices did contain dielectrics $\left(\mathrm{SiO}_{2}\right.$ and $\left.\mathrm{SiN}_{\mathrm{x}}\right)$, but not in a geometry where charging could directly influence device operation.

Mechanical and electrical properties are tightly linked in MEMS devices. Failure modes are grouped below in tables 3 and 4 as mechanical related to displacement damage, mechanical related to ionization, and electrical due to charge trapping.

Table 3: Main failure modes due to dielectric charging vs. MEMS actuation principle.

\begin{tabular}{|l|l|l|}
\hline $\begin{array}{c}\text { MEMS actuation } \\
\text { type }\end{array}$ & \multicolumn{1}{|c|}{$\begin{array}{c}\text { Sensitivity to Dielectric } \\
\text { charging }\end{array}$} & Failure modes due to dielectric charging \\
\hline Electrostatic & High (design dependent) & $\begin{array}{c}\text { Stuck comb drive, snapped-down parallel plates, } \\
\text { change in calibration of capacitive sensors }\end{array}$ \\
\hline Magnetic & Very weak & Change in breakdown voltage or wire resistance \\
\hline Piezo & Weak to medium & Calibration change (failures are due to NIEL) \\
\hline Electrothermal & Very weak & Change in breakdown voltage or wire resistance \\
\hline
\end{tabular}


Table 4: Summary of published radiation test results on MEMS devices (updated from the same table in ref [6])

\begin{tabular}{|c|c|c|c|c|c|}
\hline MEMS device & Actuation type & $\begin{array}{l}\text { Minimum dose } \\
\text { for failure }\end{array}$ & Radiation type & Failure mode & Reference \\
\hline $\begin{array}{l}\text { Analog device } \\
\text { ADXL } 150\end{array}$ & $\begin{array}{l}\text { Electrostatic } \\
\text { (comb-drive) }\end{array}$ & $27 \mathrm{krad}(\mathrm{Si})$ & Co-60 $\gamma$ & Not investigated & [34] \\
\hline $\begin{array}{l}\text { Analog device } \\
\text { ADXL } 150\end{array}$ & $\begin{array}{l}\text { Electrostatic } \\
\text { (comb-drive) }\end{array}$ & $\begin{array}{l}\text { Highly tolerant } \\
\text { (no failures } \\
\text { seen) }\end{array}$ & $\begin{array}{l}\text { Infrared laser, } \\
5.5 \mathrm{~nJ} \text { (SEE) }\end{array}$ & Not investigated & [34] \\
\hline $\begin{array}{l}\text { Analog Devices } \\
\text { ADXL 50 }\end{array}$ & $\begin{array}{l}\text { Electrostatic } \\
\text { (comb-drive) }\end{array}$ & $25 \mathrm{krad}(\mathrm{Si})$ & Co-60 $\gamma$ & $\begin{array}{c}\text { Dielectric charging in } \\
\text { device }\end{array}$ & {$[26]$} \\
\hline $\begin{array}{l}\text { Analog Devices } \\
\text { ADXL } 50\end{array}$ & $\begin{array}{l}\text { Electrostatic } \\
\text { (comb-drive) }\end{array}$ & $>50 \operatorname{krad}(\mathrm{Si})$ & $\begin{array}{l}\text { SEM localized } \\
\text { e-beam } 30 \mathrm{keV}\end{array}$ & $\begin{array}{c}\text { Dielectric charging in } \\
\text { device }\end{array}$ & [26] \\
\hline $\begin{array}{l}\text { Analog Devices } \\
\text { ADXL } 50\end{array}$ & $\begin{array}{l}\text { Electrostatic } \\
\text { (comb-drive) }\end{array}$ & $100 \mathrm{krad}(\mathrm{Si})$ & $5.5 \mathrm{MeV}$ protons & $\begin{array}{c}\text { Dielectric charging in } \\
\text { device }\end{array}$ & {$[26]$} \\
\hline $\begin{array}{l}\text { Analog Devices } \\
\text { ADXL } 50\end{array}$ & $\begin{array}{l}\text { Electrostatic } \\
\text { (comb-drive) }\end{array}$ & $100 \operatorname{krad}(\mathrm{Si})$ & $\begin{array}{c}155 \mathrm{MeV} \\
\text { protons }\end{array}$ & $\begin{array}{l}\text { Proton displacement } \\
\text { in reference circuit }\end{array}$ & [26] \\
\hline $\begin{array}{l}\text { Analog Devices } \\
\text { ADXL } 50\end{array}$ & $\begin{array}{l}\text { Electrostatic } \\
\text { (comb-drive) }\end{array}$ & $20 \mathrm{krad}(\mathrm{Si})$ & $\begin{array}{c}65 \mathrm{MeV} \text { protons } \\
\text { and heavy ion }\end{array}$ & $\begin{array}{c}\text { Dielectric charging in } \\
\text { device }\end{array}$ & $\begin{array}{l}{[33]} \\
{[25]}\end{array}$ \\
\hline $\begin{array}{l}\text { Motorola } \\
\text { XMMAS40G }\end{array}$ & Electrostatic & $4 \operatorname{krad}(\mathrm{Si})$ & Co-60 $\gamma$ & $\begin{array}{c}\text { Failure of CMOS } \\
\text { readout circuit }\end{array}$ & {$[26]$} \\
\hline $\begin{array}{l}\text { Sandia } \\
\text { microengines }\end{array}$ & $\begin{array}{l}\text { Electrostatic } \\
\text { (comb-drive) }\end{array}$ & $\begin{array}{l}1 \text { to } 100 \text { Mrad } \\
\left(\mathrm{SiO}_{2}\right) \text { bias } \\
\text { dependent }\end{array}$ & $\begin{array}{c}2 \mathrm{MeV} \text { protons, } \\
5-25 \mathrm{keV} \\
\text { electrons, } 10 \\
\mathrm{keV} \text { X-rays } \\
\end{array}$ & Dielectric charging & {$[28]$} \\
\hline $\begin{array}{l}\text { Colibrys } \\
\text { accelerometer }\end{array}$ & Electrostatic & $4-8 \mathrm{krad}$ & $\begin{array}{c}\text { Protons at } 200, \\
150,100, \text { and } 60 \\
\mathrm{MeV}\end{array}$ & $\begin{array}{l}\text { Tested with control } \\
\text { electronics }\end{array}$ & [51] \\
\hline TI DMD devices & Electrostatic & $10-15 \mathrm{krad}$ & Co-60 $\gamma$ & $\begin{array}{c}\text { Tested with control } \\
\text { electronics } \\
\text { (monolithic) } \\
\end{array}$ & [8] \\
\hline $\begin{array}{l}\text { Endevco } \\
\text { accelerometer } \\
\text { 7264B-500T }\end{array}$ & Piezoresistive & $>30 \mathrm{Mrad}$ & Co-60 $\gamma$ & $\begin{array}{c}\text { Trapped charge, } \\
\text { depletion of minority } \\
\text { carriers }\end{array}$ & {$[36]$} \\
\hline $\begin{array}{l}\text { Kulite pressure } \\
\text { transducers XTE- } \\
190-25 \mathrm{~A}\end{array}$ & Piezoresistive & $\begin{array}{c}7 \text { Mrad to }>20 \\
\text { Mrad, sample } \\
\text { dependent }\end{array}$ & Co-60 $\gamma$ & $\begin{array}{c}\text { Trapped charge, } \\
\text { depletion of minority } \\
\text { carriers }\end{array}$ & [36] [43] \\
\hline $\begin{array}{l}\text { DSTO / Analatom } \\
\text { Si strain gauge }\end{array}$ & Piezoresistive & $\begin{array}{c}10^{16} \\
\text { protons } / \mathrm{cm}^{2}\end{array}$ & $3.5 \mathrm{MeV}$ protons & $\begin{array}{l}\text { Decrease in carrier } \\
\text { density and mobility } \\
\text { (NIEL) }\end{array}$ & [40] \\
\hline $\begin{array}{l}\text { Sercalo 1x2 optical } \\
\text { switch }\end{array}$ & $\begin{array}{l}\text { Electrostatic } \\
\text { (comb-drive) }\end{array}$ & $>22.5 \mathrm{krad}(\mathrm{Si})$ & Co-60 $\gamma$ & No failures seen & {$[35]$} \\
\hline $\begin{array}{l}\text { Boston } \\
\text { Micromachines Co } \\
\text { Poly-Si } \\
\text { Micromirrors array }\end{array}$ & $\begin{array}{c}\text { Electrostatic } \\
\text { (parallel-plate) }\end{array}$ & $3 \mathrm{Mrad}(\mathrm{Si})$ & Co-60 $\gamma$ & No failure seen & [37] \\
\hline $\begin{array}{l}\text { Rockwell Scientific } \\
\text { Co } \\
\text { RF switch }\end{array}$ & $\begin{array}{c}\text { Electrostatic } \\
\text { (parallel-plate) }\end{array}$ & $30 \mathrm{krad}(\mathrm{GaAs})$ & Co-60 $\gamma$ & $\begin{array}{l}\text { Dielectric charging in } \\
\text { device (strongly } \\
\text { geometry dependent) }\end{array}$ & [27] \\
\hline $\begin{array}{l}\text { FBK-IRST ohmic } \\
\text { RF switch }\end{array}$ & $\begin{array}{c}\text { Electrostatic } \\
\text { (parallel-plate) }\end{array}$ & $\begin{array}{c}10 \mathrm{Mrad}\left(\mathrm{SiO}_{2}\right) \\
\text { proton } \\
1 \mathrm{Mrad}\left(\mathrm{SiO}_{2}\right) \\
\text { X-ray } \\
\end{array}$ & $\begin{array}{l}2 \mathrm{MeV} \text { protons } \\
10 \mathrm{keV} \text { X-ray }\end{array}$ & $\begin{array}{l}\text { Both NIEL and } \\
\text { ionizing damage }\end{array}$ & [29] \\
\hline VTI SCA 600 & Electrostatic & $50 \mathrm{krad}(\mathrm{Si})$ & Co-60 $\gamma$ & Not investigated & [34] \\
\hline
\end{tabular}




\begin{tabular}{|c|c|c|c|c|c|}
\hline accelerometer & (parallel plate) & & & & \\
\hline $\begin{array}{l}\text { VTI SCA } 600 \\
\text { accelerometer }\end{array}$ & $\begin{array}{l}\text { Electrostatic } \\
\text { (parallel plate) }\end{array}$ & $\begin{array}{l}\text { Not quantified, } \\
\text { but low }\end{array}$ & $\begin{array}{l}\text { Infrared laser, } \\
5.5 \mathrm{~nJ} \text { (SEE) }\end{array}$ & $\begin{array}{l}\text { due to latch-up in } \\
\text { CMOS electronics }\end{array}$ & [34] \\
\hline $\begin{array}{l}\text { NASA/GSFC } \\
\text { Microshutter array }\end{array}$ & $\begin{array}{l}\text { Electrostatic \& } \\
\text { electromagnetic }\end{array}$ & $\begin{array}{l}10 \text { to }>200 \mathrm{krad} \\
\text { (Si) depending } \\
\text { on drive voltage }\end{array}$ & Co- $60 \gamma$ at $60 \mathrm{~K}$ & $\begin{array}{c}\text { Charge trapping } \\
\text { (dielectric charging) }\end{array}$ & [38] \\
\hline $\begin{array}{l}\text { Polysilicon } \\
\text { electrothermal } \\
\text { actuator and } \\
\text { bimorph cantilevers }\end{array}$ & $\begin{array}{l}\text { Electrothermal } \\
\text { and CTE } \\
\text { mismatch }\end{array}$ & $>1 \mathrm{Mrad}(\mathrm{Si})$ & $\begin{array}{c}\text { Co-60 yand } 50 \\
\text { keV X-ray }\end{array}$ & No failure seen & [42] \\
\hline $\begin{array}{l}\text { Purdue wireless } \\
\text { microdosimeter }\end{array}$ & $\begin{array}{c}\text { Electrostatic } \\
\text { (parallel plate) }\end{array}$ & $\begin{array}{c}\text { Tested up to } 3 \\
\text { krad }\end{array}$ & Co-60 $\gamma$ TID & No failure seen & [41] \\
\hline $\begin{array}{l}\text { PDMS membrane } \\
\text { actuator }\end{array}$ & $\begin{array}{l}\text { Electrostatic (kV } \\
\text { artificial muscle) }\end{array}$ & $\begin{array}{l}100 \mathrm{krad}(\gamma \\
.1 \mathrm{rad} \text { (proton) } \\
\end{array}$ & $\begin{array}{c}\text { Co-60 } \gamma \text { TID } \\
\text { 3.5 MeV Proton }\end{array}$ & $\begin{array}{c}\text { PDMS stiffness } \\
\text { increased by } 2 x \text { to } 5 x\end{array}$ & [50] \\
\hline Silicon cantilevers & - & $16 \mathrm{krad}$ & Co-60 $\gamma$ TID & Stress relaxation & [52] \\
\hline $\begin{array}{l}\text { Lemoptix scanning } \\
\text { mirror }\end{array}$ & Electromagnetic & $>100$ MRad & 1-4 MeV proton & No damage & [11] \\
\hline
\end{tabular}

\subsection{Mechanical Failures due to Displacement Damage}

Even at the high end of space mission doses (several Mrad corresponding to 10 year in a GPS orbit), the mechanical properties of silicon and metals are mostly unchanged, e.g., Young's modulus and yield strength are not significantly affected. Silicon is thus considered as a structural material that is intrinsically radiation hard. This makes most Si-based MEMS devices radiation hard with respect to purely mechanical failures, but only for devices where the Young's modulus need to be stable to a few parts per thousand, for example for MOEMS, or devices that operate in two well defined states such as RF switches. It is probably not correct for RF oscillators where $10 \mathrm{ppm}$ stability is required of the resonance frequency, which is proportional to the square root of the Young's modulus. This issue is only now starting to be investigated, with protons in [11] and gamma irrational in [52], with minor effects seen to date, possibly also related to the heating due to the high dose rates.

Tazzoli et al. [29] report on the effect of $2 \mathrm{MeV}$ protons on ohmic RF switches. They observe an important degradation of insertion loss, but only a very small change in actuation voltage, and a complex post-irradiation behavior, with a surprising degradation during anneal (devices typically recover from radiation damage during annealing). They also exposed samples to $10 \mathrm{keV} \mathrm{X-rays,} \mathrm{which} \mathrm{should} \mathrm{not} \mathrm{produce} \mathrm{significant} \mathrm{displacement} \mathrm{damage,} \mathrm{and} \mathrm{observed} \mathrm{a} \mathrm{more}$ pronounced recovery than for protons. They concluded that both NIEL and ionizing damage appear to play a role in the degradation of their switches.

\subsection{Electrostatic MEMS sensors and actuators}

For electrostatic MEMS devices the main failure mode at high radiation doses is the accumulation of charge in dielectric layers, which first causes a change in the calibration of the device (essentially by applying a quasi-constant electrostatic force), and ultimately can lead to complete failure by a short circuit or continuous (undesired) actuation even at 0 volts. The failure may appear mechanical (e.g., a stuck comb-drive) but the root cause is electrical. For a given device, total ionizing dose (TID) is the main radiation parameter that quantifies the amount of charging.

Photons, electrons, and protons create electron-hole pairs in dielectrics through a number of inelastic scattering mechanisms. The carriers that survive the initial recombination move in response to the local electric field, electrons being much more mobile than holes. Carriers that become trapped lead to an effectively permanent fixed charge (decay time of hours or days). Details of charging depend on the geometry, secondary electrons emitted from nearby surfaces, and very importantly on the applied bias. Edmonds et al. [25] provided the first model of how a fixed charge under a comb-drive can lead to a force, and thus to a shift in the output voltage. Edmonds et al. [25] also developed a model for charge trapping, balancing charging from secondary electron emission with various discharge mechanisms, proving an explanation for why electron and proton irradiation produce trapped charge of opposite polarity despite both creating electron-hole pairs. Reference [32] provides a model of different charging mechanisms and simulates several geometries. 
Accelerometers, in particular monolithic comb-drive polysilicon devices manufactured by Analog Devices, have been investigated for TID effects [26], [33], [34]. The devices operate by sensing the change in capacitance as a suspended proof mass moves in response to external accelerations. It is thus very sensitive to any static charge in exposed dielectrics, and Knudson et al. [33] showed the radiation-induced output voltage shift was due to charging of a dielectric under the proof mass. The devices tested under high-energy proton and gamma-rays show degradation in the $50 \mathrm{krad}$ range (ADXL 50 and ADXL 150). For similar devices where a conducting polysilicon film was placed over the dielectric (ADXL 04), thus effectively electrically shielding any trapped charge from the active device, no radiation induced degradation was observed up to a dose of $3 \mathrm{Mrad}$ [33].

SOI bulk micromachined accelerometers from VTT, Finland, operating by measuring the capacitance between suspended parallel plates were subjected to gamma-rays, and failed at $50 \mathrm{krad}$ [34]. The sensor was packaged with a readout-ASIC, which was found to latch-up at low doses of infrared laser pulses. It was not determined if the failure at $50 \mathrm{krad}$ was due to the sensor or the ASIC. A non-monolithic approach (i.e., separate sensor and readout/control ASIC chips in one package) is an appealing approach to rapidly developing radiation tolerant sensors, as it allows choosing a radiation-tolerant ASIC (an easier task since radiation hard CMOS technology is mature), and focusing the research solely on radiation-hardening the MEMS component.

Sandia National Labs reports large shifts in CV curves measured on the comb-drives of their polysilicon microengines, reflecting radiation induced trapped charge in silicon nitride. They report a very important increase in minimum dose required to damage the devices by grounding or applying a voltage to all electrodes. Floating electrodes charge up, and cause device failure sooner than electrodes whose potential is externally fixed [28].

Capacitive RF switches require a dielectric film to separate a fixed electrode from movable membrane. One of the common failure modes of RF switches is charging of this dielectric due to the large applied electric fields. An RF switch from HRL Laboratories was successfully operated dynamically up to a dose of 1 Mrad [39]. RF switches from Rockwell Scientific Company reported in [27] showed no change in static characteristics at doses of up to 150 krad for one design developed to reduce dielectric charging, For a more conventional design, the device's calibration started to change at doses of $10 \mathrm{krad}$, although the device continued to operate after doses of $300 \mathrm{krad}$, but with an $80 \%$ increase in required drive voltage. The difference in dose required for degradation between the two devices is due to the different location of the dielectric layers. The configuration that is more radiation-tolerant has no dielectric between the moving parts.

To gain a better understanding of the effect of charging on the dielectric in RF MEMS switches in space applications, there have been a number of studies using metal-insulator-metal capacitors as test vehicles, exposing them to $5 \mathrm{MeV}$ alpha particles [47],[48]. This technique allows a straightforward measurement of the trapped charge, and can allow for rapid comparison of different dielectrics.

A JPL study on MOEMS polysilicon mirrors arrays based on a parallel plate actuation scheme with no exposed dielectric between fixed and moving electrodes showed no damage at doses of $3 \mathrm{Mrad}$ gamma-rays [37]. A microshutter array designed to be used on a spectrometer on the James Webb Space Telescope (JWST) was tested up to $200 \mathrm{krad}$ [38], which is the expected lifetime dose expected for the instrument which is located outside the spacecraft in a second Lagrange point (L2) orbit with little shielding. The device uses an electromagnetic force to move each microshutter, consisting of a multilayer of two dielectrics and two metals, which is then held in place with an electrostatic force. The devices were tested and irradiated at $60 \mathrm{~K}$. The devices were found to be sensitive to gamma-rays at $20 \mathrm{krad}$ for the lowest holding voltage used. The severity of the effect was strongly dependent on the holding voltage used. At higher holding voltages $(20 \mathrm{~V})$, no meaningful degradation was seen up to $200 \mathrm{krad}$, presumably because the larger holding voltage gives rise to a larger electrostatic force, overcoming the force due to trapped charges.

Texas Instrument's DMD device has been proposed for use in a multi-object spectrometer in future space-based telescopes. Zamkotsian et al [8] have performed TID (Co-60) and proton irradiation of $2048 \times 1080$ mirror chips, observing a degradation near $15 \mathrm{krad}$, which they report could be dealt with by shielding for their proposed mission. The TI micromirrors are built on a SRAM CMOS circuit, and the root cause of failure was not determined (on chip- drive circuitry or micromirrors). 


\subsection{Piezoresistive and Piezoelectric MEMS}

A piezoelectric mirror array developed by JPL and Pennsylvania State University based on PZT (lead-zirconate titanate) was functional up to $1 \mathrm{Mrad}$, but at $20 \mathrm{krad}$ started exhibiting changes in mirror deflection compared to unirradiated samples, as well as an important increase in leakage current though the PZT [37]. The authors attributted the change in device characteristics to charge trapped in the PZT film.

The radiation sensitivity of micromachined piezoresistive silicon accelerometers and pressure sensors are reported in references [36], [40], [43], [44]. In all cases an increase in resistance of the piezoresistive elements are observed. Marinaro et al. [40] find a nearly linear relation between the resistance of the piezoresistor in their single-crystal silicon strain gauge and the fluence of $3.5 \mathrm{MeV}$ protons. They observed changes for fluences of the order of $10^{16} \mathrm{~cm}^{-2}$, corresponding to roughly 10 years in MEO (Medium Earth Orbit). They attribute the increase in resistance to the NIEL component of the radiation, leading to majority charge removal due to displacement damage serving as trapping centers, and to a reduction in carrier mobility.

Holbert et al. [36] and McCready et al. [43] studied the response of piezoresistive MEMS accelerometers and pressure sensors to high gamma-ray doses and pulsed neutrons. They observed a gradual shift in output of Endevco 7264B-500T accelerometers with gamma-ray doses up to $73 \mathrm{Mrad}$, with no catastrophic failures, and were able to recalibrate the devices post-irradiation. Results were less consistent for Kulite XT-190-25A pressure transducers, with two devices failing suddenly at 7 and $25 \mathrm{Mrad}$, and four others still operating at after $20 \mathrm{Mrad}$, with a shift in output voltage. Holbert et al. [36] correlate the increase in resistance of the piezoresistors to the formation of trapped hole charges. They show how this trapped charge in oxide layer surrounding the piezoresistor can induce a depletion region in the semiconductor, thus increasing the device resistance. They conclude that n-type piezoresistors with the largest cross-section will be the most radiation tolerant, though there may be a tradeoff of sensitivity vs. radiation tolerance.

\subsection{Thermal actuators}

Polysilicon thermal actuators and gold/polysilicon bimorph cantilevers were investigated by Caffey et al. [42] under ${ }^{60} \mathrm{Co}$ gamma-rays and $50 \mathrm{keV}$ X-rays. No degradation of the devices was observed at $1 \mathrm{Mrad}$, the maximum dose used. This is in line with the understanding that electrothermal devices are for the most part insensitive to dielectric charging, as long as there is no exposed dielectric near the active element.

\section{SUGGESTIONS FOR MAKING MEMS DEVICE MORE RADIATION TOLERANT}

MEMS operating on electrostatic principles are the most sensitive to charge accumulation in dielectric layers, which is the main influence of ionizing radiation on MEMS devices. In contrast, thermally and electromagnetically actuated MEMS are much more radiation tolerant. MEMS operating on piezoresitive principles, while not showing any threshold for radiation sensitivity, do not fail catastrophically until doses of several Mrad are exceeded.

Reference [4] (chapter 4) contains a detailed discussion of possible geometry changes, charge dissipation layers, and other approaches that can minimize the effect on device performance of charge that is trapped in dielectric films for electrostatic MEMS devices. The same strategies used to mitigate dielectric charging in capacitive RF MEMS switches, such as replacing dielectric films with arrays of dielectric posts, using pull-up electrodes, and selecting different dielectric materials are all applicable to increasing radiation tolerance, see e.g. [53]. It is essential that all conductors be at well-defined potentials and not be left to float to avoid undesired electrostatic forces. Other techniques that eliminate or minimize charging effects include:

- A geometry change to eliminate the dielectric from between moving surfaces, and from under moving surfaces.

- Shielding, by covering exposed dielectric with a conductor as at well-defined potential, as in [33].

- Change of dielectric material to one with lower trap density

Since electrothermal and electromagnetic actuation principles are intrinsically more radiation tolerant than electrostatic operation, these actuation principles should be considered for applications where high radiation doses are expected. For instance the electromagnetically actuated mirror from Lemoptix (Lausanne, Switzerland) were tested to doses of over $100 \mathrm{Mrad}$ protons with no significant change in performance [11]. 


\section{CONCLUSIONS}

The failures reported in Table 4 generally occur at doses corresponding to several years to several hundreds of years of operation in orbit, especially when shielding from the package is taken into account. Furthermore the failures modes are well enough understood that effective mitigation strategies can be implemented to increase the radiation hardness of MEMS. So while further research is needed into the effect of radiation on MEMS, in particular into qualification methods to accelerate adoption of MEMS in space, radiation sensitivity will not be the limiting factor for widespread acceptance of MEMS in space applications.

\section{REFERENCES}

[1] "MEMS Accelerometer, Gyroscope and IMU Market 2008-2013", Yole Development report, http://www.yole.fr/pagesAn/products/reports.asp

[2] Shea, H. "MEMS for pico- to micro-satellites", Proc. SPIE 7208, 72080M (2009)

[3] De Rooij, N.F., Gautsch, S., Briand, D., Marxer, C., Mileti, G., Noell, W., Shea, H., Staufer, U., Van Der Schoot, B, "MEMS for space", TRANSDUCERS 2009 - 15th International Conference on Solid-State Sensors, Actuators and Microsystems, art. no. 5285575, pp. 17-24. (2009)

[4] Hartzell, A., da Silva, M. and Shea, H. [MEMS Reliability], Springer (2011), ISBN 978-1-4419-6017-7

[5] Iniewski, K., [Radiation Effects in Semiconductors], CRC Press, (2010)

[6] Shea, H, "Radiation sensitivity of microelectromechanical system devices", J. Micro/Nanolith. MEMS MOEMS 8(3), 031303 (2009)

[7] Osiander, R, Garrison Darrin, M.A, Champion, J.L., [MEMS and Microstructures in Aerospace Applications], Taylor and Francis (2006). See in particular chapter 5 by. S. Buchner.

[8] Zamkotsian, F. et al, "Space evaluation of 2048 x 1080 mirrors DMD chip for ESA's EUCLID Mission", Proc. SPIE 7731, 773130 (2010)

[9] SRIM by James F. Ziegler: http://www.srim.org/

[10] MEMSRAD study led by EADS Astrium, https://escies.org/radlab/reports.jsp?year=2009

[11] Gomes, J. and Shea, H. "Displacement damage effects in silicon MEMS at high proton doses", Proc SPIE 7928, (2011)

[12] SPENVIS, the Space Environment Information System, http://www.spenvis.oma.be/

[13] Holmes-Siedle, A. and Adams, L., [Handbook of radiation effects], Oxford University press, 2nd edition, (2002)

[14] European Cooperation for Space Standardization, document ESCC Basic Specification 22900 for Total Dose Steady-State Irradiation Test Method, available at: $\underline{\text { https: } / / \text { escies.org/ReadArticle?docId }=229}$

[15] European Cooperation for Space Standardization, document ESCC Basic Specification 25100 for Single Event Effects Test Method and Guidelines. Available at: https://escies.org/ReadArticle?docId=229

[16]B. Stark, "MEMS Reliability Assurance Guidelines for Space Applications", JPL Publication 99-1, 1999

[17] T. George, "Overview of MEMS/NEMS technology development for space applications at NASA/JPL", Proc. of SPIE 5116, 136 (2003)

[18] S. Barthe, F. Pressecq, L. Marchand, "MEMS for space applications: a reliability study", 4th Round Table on MNT for Space. 20-22 May 2003, ESTEC, Noordwijk, Netherlands.

[19] C. Rossi et al., "Matrix of $10 \times 10$ addressed solid propellant microthrusters: Review of the technologies", Sensors and Actuators A: Physical, Vol. 126, pp. 241-252. (2006)

[20] J. Köhler, J. Bejhed, H. Kratz, F. Bruhn, U. Lindberg, K. Hjort, L. Stenmark, “A hybrid cold gas microthruster system for spacecraft", Sensors and Actuators A (Physical), A97-98:587-98, April 2002.

[21] European Space Agency Procedures Standards and Specifications, document ESA PSS-01-609 (May 1993) Radiation Design Handbook, available at: https://escies.org/ReadArticle?docId=263

[22] European Cooperation for Space Standardization, document ECSS-E-ST-10-04C Space environment, available at: http://www.ecss.nl/forums/ecss/dispatch.cgi/standards/showFile/100700/d20081115082809/No/ECSS-E-ST10-04C(15November2008).pdf

[23] O. Tabata, T. Tsuchiya, O. Brand, G:. Fedder, C. Hierold, J.. Korvink, eds., , [Reliability of MEMS: Testing of Materials and Devices] (Advanced Micro and Nanosystems series), Wiley-VCH (2008) 
[24] Shea, H., "Reliability of MEMS for space applications", Proc. of SPIE vo. 6111, 61110A, (2006)

[25] L.D. Edmonds, G.M. Swift, C.I. Lee, "Radiation response of a MEMS accelerometers: an electrostatic force", IEEE Trans. Nucl. Sci. 45 2779-2788 (1998)

[26] C.I. Lee, A.H. Johnston, W.C. Tang, C.E. Barnes, "Total dose effects on micromechanical systems (MEMS): accelerometers", IEEE Trans. Nucl. Sci. 43 3127-3132 (1996)

[27] McClure, S., et al, "Radiation effects in microelectromechanical systems (MEMS): RF relays," IEEE Trans. Nucl. Sci., vol. 49, pp. 3197-3202, (2002)

[28] L. P. Schanwald et al., "Radiation effects on surface micromachined comb drives and microengines," IEEE Trans. Nucl. Sci., vol. 45, no. 6, pp. 2789-2798, (1998)

[29] A. Tazzoli, et al., "Radiation sensitivity of OHAMIC RF-MEMS switches for spatial applications", Proc. 22nd IEEE Int. Conf. on Micro Electro Mechanical System (MEMS 2009). (2009)

[30] A. Neels et al., "Reliability and failure in single crystal silicon MEMS devices", Microelectronics Reliability 48 pp 1245-1247, (2008)

[31] A. Dommann, A.Enzler, N. Onda, Advanced X-ray analysis Techniques to Investigate Aging of Micromachined Silicon Actuators for space Application, Microelectronics Reliability, 43 1099-1103, (2003)

[32] V. Theonas et al., "RF MEMS dielectric sensitivity to electromagnetic radiation", Sensors and Actuators A, 132, pp 25-33, (2006)

[33] A.R. Knudson, S. Buchner, P. McDonald, W.J. Stapor, A.B. Campbell, K.S. Grabowski, D.L. Knies, “The effects of radiation on MEMS accelerometers", IEEE Trans. Nucl. Sci. 43, 3122-3126. (1996)

[34] Coumar, O., et al, "Total Dose Effects and SEE Screening on MEMS COTS Accelerometers", IEEE Radiation Effects Data Workshop, pp.125 - 129 (2004)

[35] G. Quadri, J.M. Nicot, G. Guibaud, and O. Gilard, "Optomechanical Microswitch Behavior in a Space Radiation Environment" IEEE Transactions on Nuclear Science, Vol. 52, No. 5, p. 1795, (2005)

[36] K.E. Holbert, J.A. Nessel, S.S. McCready, A.S. Heger, and T.H. Harlow, "Response of piezoresistive MEMS accelerometers and pressure transducers to high gamma dose", IEEE Transactions on Nuclear Science, Vol 50, Iss. 6, pp $1852-1859$ (2003)

[37] T.F. Miyahira, et al., "Total dose degradation of MEMS optical mirrors", IEEE Transactions on Nuclear Science, Vol 50, Iss 6, Part 1, pp. 1860 - 1866 (2003)

[38] S. Buchner et al., "Response of a MEMS Microshutter operating at $60 \mathrm{~K}$ to ionizing radiation", IEEE Trans. on Nuclear Science, vol.5 4, no. 6, p 2463, (2007)

[39]R. N. Schwartz et al., "Gamma-ray radiation effects on RF MEMS switches", Proc. 2000 IEEE Microelectronics Reliability and Qualification Workshop, p. IV.6. (2000)

[40]D. Marinaro et al., "Proton radiation effects on MEMS silicon strain gauges", IEEE Trans. On Nuclear Science, vol.55, no.3, p 1714, (2008)

[41] C. Son and B. Ziaie, "An implantable wireless microdosimeter for radiation oncology", Proceedings of IEEE Conference on Micro Electro Mechanical Systems (MEMS 2008), p. 256. (2008)

[42] J.R. Caffey and P.E. Kladitis, "The effects of ionizing radiation on microelectromechanical systems (MEMS) actuators: electrostatic, electrothermal, and bimorph", Micro Electro Mechanical Systems, 2004. 17th IEEE International Conference on. (MEMS), pp. 133- 136 (2004)

[43] S.S. McCready et al., "Piezoresistive micromechanical transducer operation in a pulsed neutron and gamma ray environment", IEEE Radiation Effects Data Workshop, pp. 181- 186 (2002)

[44] S.-Y. Zhu et al., "Total dose radiation effects of pressure sensors fabricated on Unibond-SOI materials", Nucl. Sci. Tech., vol. 12, pp. 209-214, (2001)

[45] C.L. Allred et al., "Neutron irradiation-induced dimensional changes in MEMS glass substrates", Nuclear Instruments and Methods in Physics Research B, 264, pp 66-72, (2007)

[46] M.J. Key et al., "On the radiation tolerance of SU-8, a new material for gaseous microstructure radiation detector fabrication", Radiation Physics and Chemistry, 71, pp. 1003-1007, (2004)

[47] J. Ruan et al., "Alpha particle radiation effects in RF MEMS capacitive switches", Microelectronics Reliability 48, pp. 1241-1244, (2008)

[48]E. Papandreou et al., "Structure dependent charging process in RF MEMS capacitive switches", Microelectronics Reliability 47, pp. 1812-1817, (2007)

[49] W M van Spengen et al., "A comprehensive model to predict the charging and reliability of capacitive RF MEMS switches”, J. Micromech. Microeng. 14, 514-521, (2004) 
[50] Niklaus, M., Rosset, S., and Shea, H., "Array of lenses with individually tunable focal-length based on transparent ion-implanted EAPs", Proc. of SPIE Vol. 7642, 76422K (2010)

[51] Oudea, C et al., "Single Event Effects in MEMS Accelerometers", IEEE Radiation Effects Data Workshop, pp 94-98 (2009)

[52] Wang, L., Huang, QA, Tang, J., and Luo, J., "Radiation Effects on Mechanical Characteristics of MEMS", IEEE Proc. of $16^{\text {th }}$ IPFA (2009)

[53] Goldsmith, C.L., et al, "Understanding and improving longevity in RF MEMS capacitive switches," SPIE Proc. vol. 6884 , no. $03,(2008)$ 